\title{
SIMULAÇÃO DA CONCENTRAÇÃO DE MATERIAL PARTICULADO INALÁVEL DE ORIGEM VEICULAR EM UMA INTERSEÇÃO SINALIZADA DE UBERLÂNDIA-MG
}

\author{
${ }^{1}$ Livia G. Soares, ${ }^{1}$ Cláudio A. Vieira Filho, ${ }^{1}$ Helder Hamada, ${ }^{2}$ Marcus Vinícius de O \\ Fernandes e ${ }^{3}$ Marcos A. S. Barrozo \\ ${ }^{1}$ Discente de Iniciação Científica do curso de Engenharia Química UFU/MG \\ ${ }^{2}$ Discente do curso de Mestrado em Engenharia Química UFU/MG \\ ${ }^{3}$ Professor da Faculdade de Engenharia Química da UFU/MG \\ e-mail:masbarrozo@ufu.br
}

\begin{abstract}
RESUMO - O desenvolvimento econômico e social das populações pode provocar o incremento de emissões atmosféricas, sobretudo as oriundas da exaustão das frotas automotivas. Estas constituem fontes difusas de diversos poluentes como as partículas inaláveis $\left(\mathrm{MP}_{10}\right)$. A quantificação de partículas suspensas na atmosfera da cidade de Uberlândia-MG é executada pela Faculdade de Engenharia Química da Universidade Federal de Uberlândia desde o ano de 2003 nas proximidades do terminal de ônibus coletivos no centro da cidade. O objetivo principal deste trabalho foi empregar o modelo matemático Gaussiano CAL3QHC na predição dos níveis de concentração de $\mathrm{MP}_{10}$ de origem veicular para o ano de 2012 e posterior validação dos resultados mediante a comparação com os dados experimentais. Os resultados alcançados na simulação numérica das concentrações de $\mathrm{MP}_{10}$ revelaram a capacidade preditiva do modelo CAL3QHC, bem como um desempenho moderado do modelo perante as hipóteses consideradas. As imprecisões do modelo foram atribuídas à inconsistência de algumas variáveis como o fator de emissão veicular e as concentrações de background.
\end{abstract}

\section{INTRODUÇÃO}

A demanda por transportes e, consequentemente, o incremento constante das frotas veiculares movidas por combustíveis fósseis constituem importantes fatores responsáveis por grande parte das emissões de poluentes atmosféricos em todo o mundo. Nos estudos de qualidade do ar é muito importante considerar o papel das condições da atmosfera que são afetadas pela variação climática observada no decorrer de um dado período.

A poluição do ar por material particulado em suspensão merece destaque devido à sua extensa faixa de tamanhos e à complexidade de sua composição, que podem acarretar graves problemas, sobretudo no sistema respiratório. Atualmente são conhecidas diversas técnicas de monitoramento de particulados. Entretanto, os dados de monitoramento por si só não possuem a capacidade preditiva. Para o preenchimento desta lacuna, os estudos atuais recorrem-se à utilização da modelagem matemática.

\section{MODELO CAL3QHC}



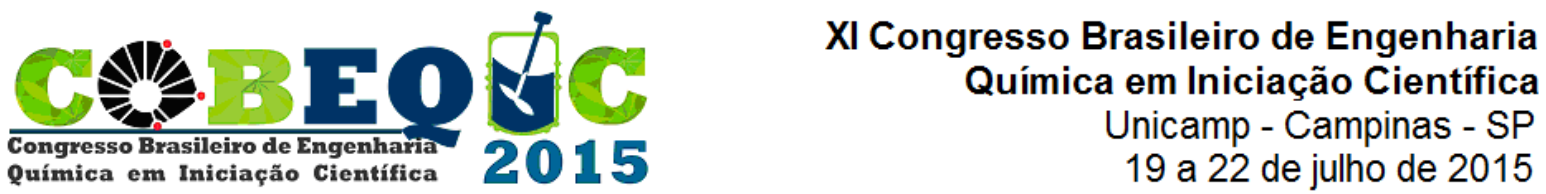

O CAL3QHC é o modelo recomendado pela USEPA para avaliação da dispersão de CO (Monóxido de Carbono) e MP em interseções de vias sinalizadas. O modelo inclui o CALINE 3, desenvolvido para predizer as concentrações de poluentes próximas a uma via de tráfego, originadas da exaustão de veículos sob condições de fluxo livre e ainda incorpora um algoritmo para a estimativa do comprimento das filas formadas em interseções sinalizadas, contabilizando a contribuição das emissões dos veículos parados.

\subsection{Zona de Mistura Inicial}

O CALINE 3 considera a região imediatamente acima da via como uma zona de turbulência e emissões uniformes, designada zona de mistura inicial - SGZ1, representada esquematicamente na Figura 1. Esta região consiste na largura da via (somatório das faixas de rolamento) adicionada de 3 metros em cada lado. Essa adição visa à consideração da dispersão horizontal da pluma gerada devido à turbulência causada pela movimentação dos veículos. Dentro da zona de mistura a turbulência mecânica, criada pelo movimento dos automóveis e a turbulência térmica, originada pela exaustão dos gases quentes pelo escapamento são fenômenos dominantes na dispersão.

Figura 1 - Representação da zona de mistura inicial. Fonte: Tavares (2009).

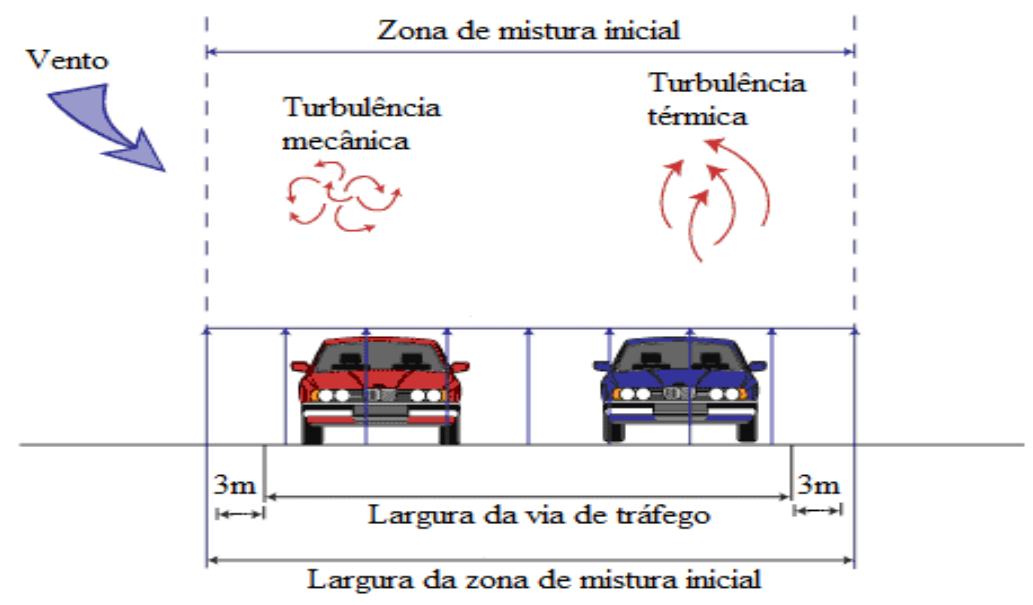

\subsection{Links de Fluxo Livre e Links de Fila}

Um link de fluxo livre e link de fila são definidos como segmentos retos de uma via com largura, altura, volume de tráfego, velocidade de deslocamento e fator de emissões constantes. A localização do link de fluxo livre é especificada pelas coordenadas dos pontos inicial (x1, y1) e final (x2, y2), como ilustra a Figura 2-a e a localização do link de fila é determinada pelo seu ponto inicial $(\mathrm{x} 1, \mathrm{y} 1)$, posicionado sobre a faixa de retenção da via e um ponto final arbitrário $(\mathrm{x} 2, \mathrm{y} 2)$ ao longo da linha onde a fila é formada Figura 2-b. 

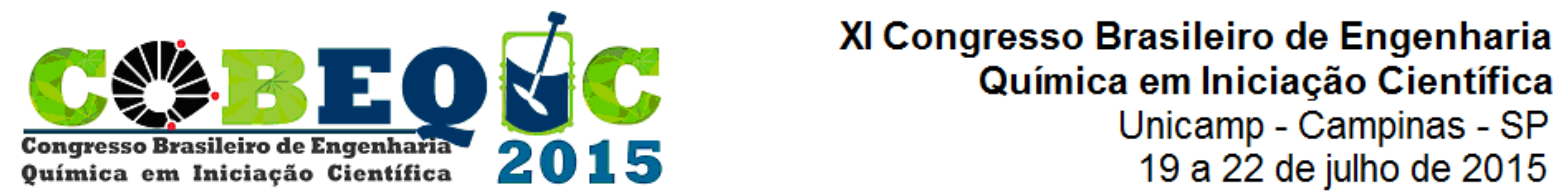

Figura 2 - Representação esquemática dos links: (a) fluxo livre; (b) fila. Fonte: Adaptado de EPA (1995).

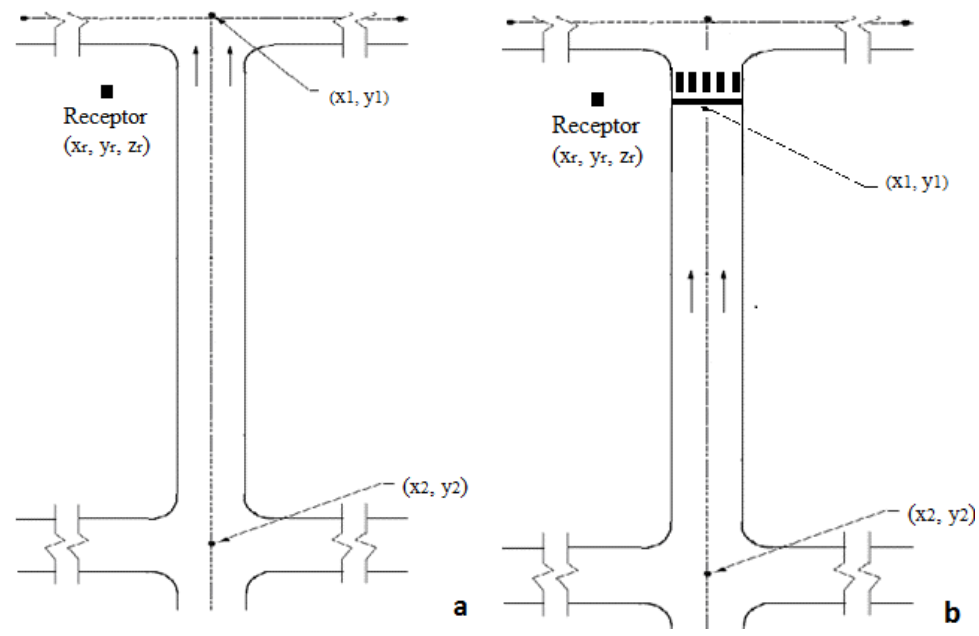

\section{MATERIAIS E MÉTODOS}

Com os dados coletados pelo amostrador de grande volume - AGVMP10. E dos dados meteorológicos, foram necessários outros dados para ser feita a modelagem matemática, através do programa CALINE 3.

\subsection{Frota Veicular de Uberlândia}

Neste trabalho foi considerada a frota circulante de veículos movidos a gasolina e a diesel e com ano de fabricação desde 1982 até 2012 com base nos dados do DENATRAN. Esta faixa etária foi selecionada devido ao fato de os veículos com mais de 30 anos comporem uma parcela pouco significativa da frota.

Para a determinação da frota movida a gasolina foi necessário ainda considerar a parcela de veículos bicombustíveis - flex. Por fim, o cálculo da frota flex abastecida com gasolina foi identificado a partir da equação 1:

$$
N V_{g}=F_{\text {flex }} \times\left(1-f_{e}\right)
$$

Onde:

$N V g=$ Número de veículos flex abastecidos com gasolina;

$F_{\text {flex }}=$ Frota total de veículos flex;

$f e=$ fração de automóveis flex abastecidos com etanol.

\subsection{Fatores de Emissão}

Nesta pesquisa foi adotado o valor de $0,057 \mathrm{~g} / \mathrm{km}$ para veículos leves como fator de emissão de particulados, o mesmo parâmetro adotado pela CETESB(2013). Tal escore representa mais fielmente as características dos veículos componentes da frota de Uberlândia.

Para calcular o fator de emissão médio dos veículos a diesel foi utilizado a equação 2. 


$$
F M^{d}=\sum_{i} F E_{i}^{d} \times N V_{i}^{d}
$$

Onde:

$F M d$ = fator de emissão médio da frota movida a diesel $(\mathrm{g} / \mathrm{km})$;

$i=$ cada fase $\mathrm{P}$ do PROCONVE;

$F E_{i}^{d}=$ fator de emissão dos veículos a diesel pertencente à fase i (g/veículo km);

$N V_{i}^{d}=$ frota de veículos movida a diesel pertencente à fase $i$.

O fator de emissão composto, que representa toda a frota considerada foi calculado através da seguinte expressão:

$F E_{c}=\frac{F M^{g} \times N V^{g}+F M^{d} \times N V^{d}}{N V}$

(3)

Onde:

$F E_{c}=$ fator de emissão composto (g/veículo $\mathrm{km}$ );

$F M^{g}$ = fator de emissão médio da frota movida a gasolina $(\mathrm{g} / \mathrm{km})$;

$N \nu^{g}=$ frota total de veículos movidos a gasolina1;

$F M^{d}=$ fator de emissão médio da frota movida a diesel $(\mathrm{g} / \mathrm{km})$;

$N V^{d}=$ frota total de veículos movidos a diesel;

$N V=$ frota total considerada.

Com relação à determinação dos fatores de emissão para veículos parados em fila, no Brasil não são realizados ensaios para esse fim. Na maioria dos trabalhos da área são adotados os fatores estabelecidos pela USEPA (1995), cujo valor médio para MP10 é de 2,59 g/h.

\subsection{Determinação dos Links e Receptores}

Para este estudo foram adotados os 4 trechos de 150 metros de comprimento a montante e a jusante do cruzamento a onde tem maior concentração de veículos e a entrada e saída dos ônibus. A Figura 4a ilustra a adoção de 7 links de fluxo livre nas duas avenidas. A Figura 4b ilustra os 3 links de fila adotados, onde as setas indicam o sentido de formação das filas.

Figura 4 - Representação esquemática dos links: (a) fluxo livre; (b) fila. 


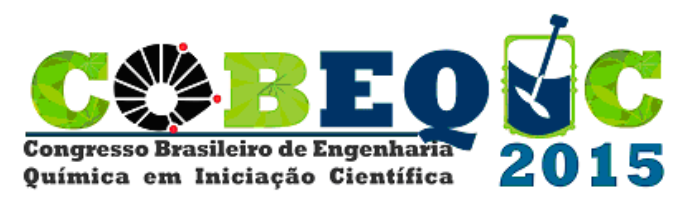

\section{Congresso Brasileiro de Engenharia \\ Química em Iniciação Científica \\ Unicamp - Campinas - SP \\ 19 a 22 de julho de 2015}

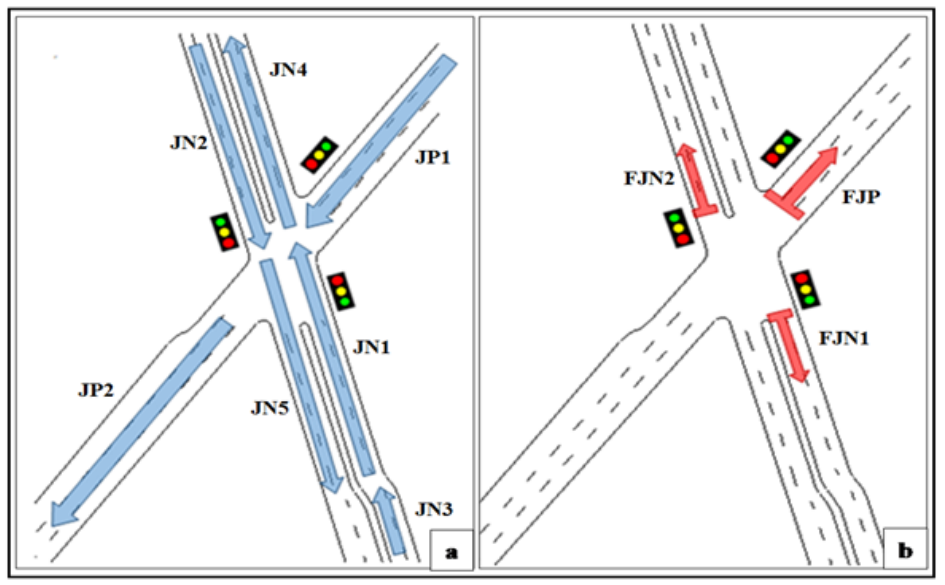

A dispersão do MP10 na atmosfera da região foi avaliada mediante a consideração de uma malha de pontos com espaçamentos de 20 metros, totalizando uma área de $14400 \mathrm{~m}^{2}$, conforme a Figura 5.

Figura 5 Representação e identificação dos receptores.

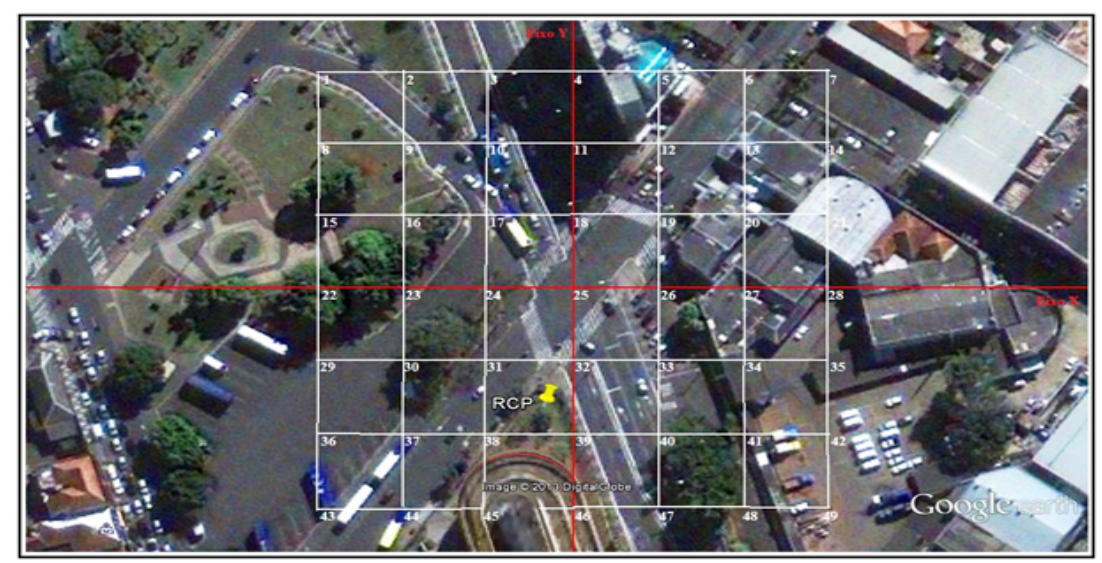

A concentração background (concentração de MP10 devido a outras fontes) é uma variável de entrada opcional do modelo CAL3QHC, porém, de grande importância na obtenção dos resultados, pois sua definição criteriosa pode ser fundamental para o nível de precisão das simulações.

\section{RESULTADOS E DISCUSSÃO}

Para a obtenção dos resultados das concentrações de MP10 é realizada a coleta de três em três dias da semana com um período de amostragem de 24 horas, no final de cada mês é obtida uma media dos valores observadas no receptor discreto e preditas pelo modelo (Co e Cp) para o ano de 2012 foram plotados conforme a Figura 6.

Figura 6 - Comparação entre os resultados experimentais e simulados das concentrações de MP 10 em 2012 na cidade de Uberlândia-MG. 


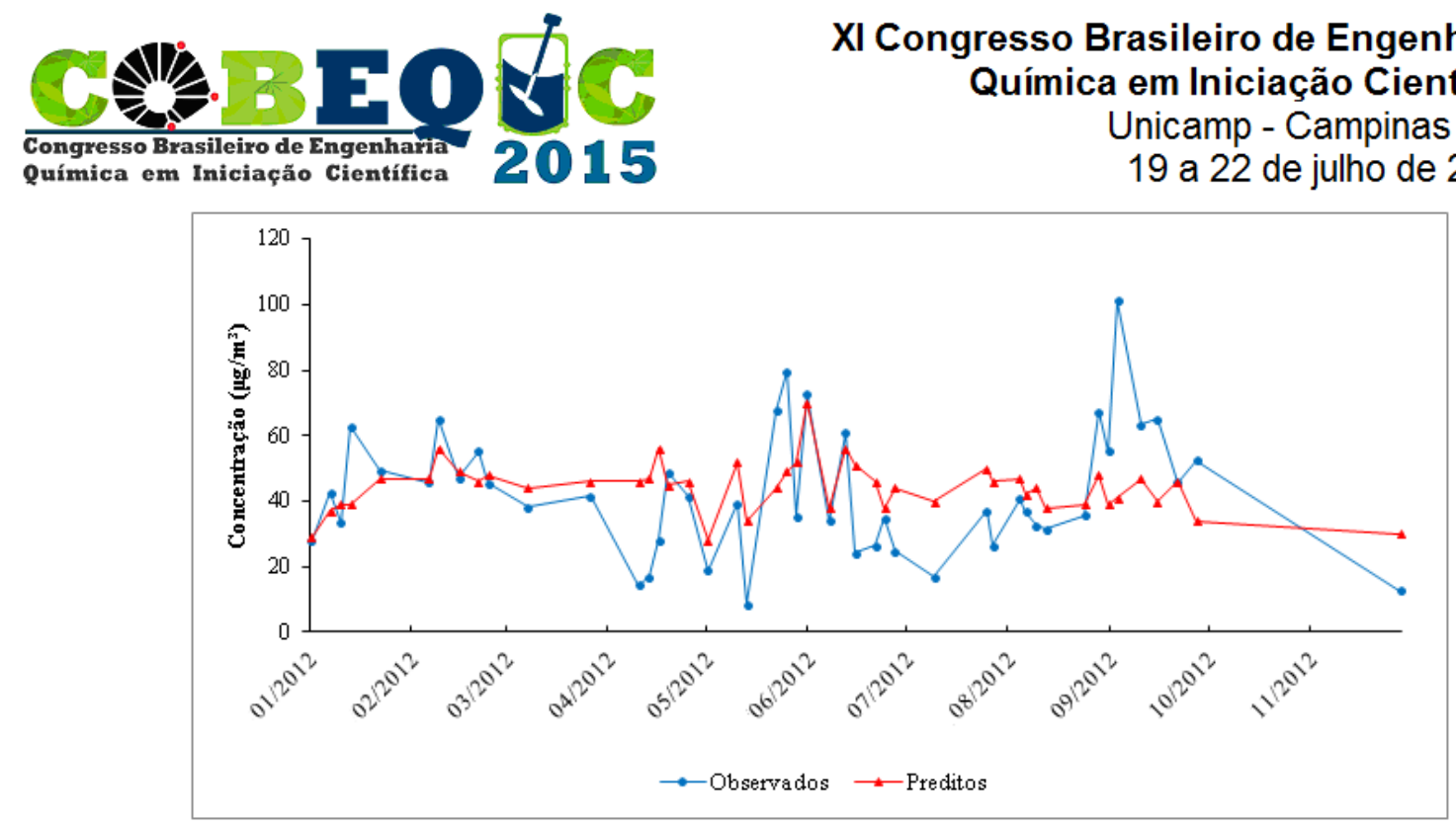

A partir da análise da Figura 6 é possível notar que na comparação entre os resultados experimentais e simulados o modelo apresentou alguns pontos de imprecisão na simulação das concentrações de MP10 no período selecionado, sobretudo na ocorrência de valores muito altos ou muito baixos de concentração.

\section{CONCLUSÕES}

A análise das respostas do modelo CAL3QHC, empregado na simulação das concentrações de MP10 no ano de 2012 permitiu a avaliação da capacidade preditiva, bem como do desempenho do modelo. Acerca da modelagem, Chegou-se as seguintes conclusões:

- De maneira geral o modelo CAL3QHC apresentou desempenho moderado na previsão do campo de concentrações de MP10.

- As inconsistências verificadas nos resultados do modelo podem ser atribuídas a diversos fatores como: a adoção da concentração de background constante para todos os receptores considerados; a adoção de fatores de emissão não totalmente coerentes com a frota considerada; as emissões geradas a partir do tráfego de ônibus no interior do terminal; existência de outras fontes emissoras, tais como as partículas resultantes do desgaste de pneus e freios dos veículos, poeira ressuspensa do solo, emissões originadas nos cruzamentos vizinhos, entre outros. A correção de tais imprecisões será possível mediante a execução de pesquisas mais detalhadas acerca da determinação dos parâmetros supracitados

O conhecimento da variação temporal e espacial da concentração de contaminantes atmosféricos em uma dada região é de suma importância para a adoção de medidas regulatórias que previnam a ocorrência de episódios severos de poluição. Embora a concordância entre os resultados experimentais e os fornecidos pelo modelo CAL3QHC tenha sido moderada, a modelagem matemática da dispersão atmosférica, em seu sentido amplo, revela-se como uma importante ferramenta de auxílio à administração pública no intuito de manter o controle dos níveis de poluição.

\section{NOMENCLATURA}

AGV - Amostrador de Grande Volume

CAL3QHC - California Line Source for Queuing and Hot Spots Calculations

CALINE - California Line Source

CETESB - Companhia de Tecnologia de Saneamento Ambiental 


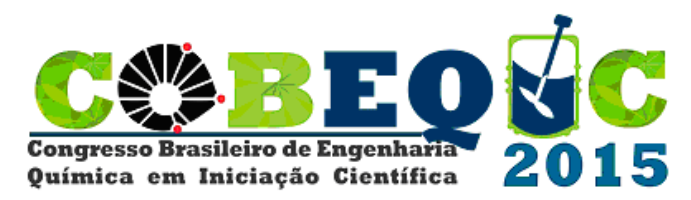

\section{Congresso Brasileiro de Engenharia \\ Química em Iniciação Científica \\ Unicamp - Campinas - SP \\ 19 a 22 de julho de 2015}

Co - Concentração observada

$\mathrm{Cp}$ - Concentração predita

DENATRAN - Departamento Nacional de Trânsito

EPA - Environmental Protection Agency

FEQUI - Faculdade de Engenharia Química

MP10 - Material Particulado com diâmetro menor que 10 micrômetros

MP - Material Particulado

PROCONVE - Programa de Controle da Poluição do Ar por Veículos Automotores

UFU - Universidade Federal de Uberlândia

\section{REFERÊNCIAS}

CETESB (São Paulo). Qualidade do ar no estado de São Paulo 2012, São Paulo: CETESB, 2013. $123 \mathrm{p}$.

UNITED STATES ENVIRONMENTAL PROTECTION AGENCY. User's Guide to CAL3QHC Version 2.0: a modeling methodology for predicting pollutant concentrations near roadway intersections. EPA-454/R-92-006, U.S. EPA: Office of Air Quality Planning and Standards, Research Triangle Park, North Carolina, 1995. 115p.

TAVARES, F. V. F. Estudo do processo de dispersão de emissões veiculares em uma microrregião de Belo Horizonte utilizando simulação numérica. 2009. 131f. Dissertação (Mestrado) - Centro de Desenvolvimento da Tecnologia Nuclear, Comissão Nacional de Energia Nuclear, Belo Horizonte, 2009. 